\title{
ГРАФОАНАЛИТИЧЕСКАЯ МОДЕЛЬ РАСПРОСТРАНЕНИЯ ИНФОРМАЦИИ ОБ ИННОВАЦИОННОМ ЛЕКАРСТВЕННОМ СРЕДСТВЕ
}

Бухаров Д.Н.

\author{
ВлГУ им. А.Г. и Н.Г. Столетовых, г. Владимир, Россия
}

Предложена модель распространения инновационного лекарственного средства, которая может применяться для оценки и прогнозирования $u$ управления данным процессом. Процесс распространения инновачионного лекарственного средства моделируется в графоаналитическом приближении как случайный взвешенный граф, для которого оченивается кратчайшее расстояние от источника информации о инновачионном лекарственном средстве, до интересующего приемника, по алгоритму Дейкстры. Предложенная модель была реализована в среде MATLAB и позволяет в первом приближении оценить процесс распространения инновационного лекарственного средства.

Ключевые слова: моделирование, граф, распространение инноваций, алгоритм Дийкстры, MATLAB.

На сегодняшний день здоровье населения и здравоохранении являются одними из наиболее важных тем, с точки зрения общества и государственного управления. Поэтому медицинская помощь выполняет важную роль в современном обществе и является объектом особого внимания со стороны органов управления. В связи с этим в современных реалиях большое значение получают совместное развитие инновационной составляющей и инновационного потенциала экономики и медицины $[1,2]$. При таких условиях инновационная медицинская технология, внедряемая рационально с точки зрения экономики, может привести к значительному положительному экономическому эффекту. Наиболее очевидным такой эффект будет применительно к оценке эффекта от внедрения и распространения инновационного лекарственного средства.

В связи с этим возникает задача планирования и управления процессом распространения инновационного лекарственного средства, которая может быть реализована в первом приближении с использованием аппарата компьютерного математического моделирования.

Определенные ориентиры для оценки и прогнозирования такого процесса можно получить на основе моделирования тенденций распространения информации о новом лекарственном средстве среди докторов. Одним из хорошо зарекомендовавших себя приближений для моделирования таких процессов является модель, на основе теории сетей и графов. 
В рамках такой модели рассматривается сообщество врачей, образующее социальную сеть, состоящую из контактов участников друг с другом, по которой происходит распространение информации о новом лекарственном средстве от источника информации.

Такую социальную сеть удобно представлять в относительных единицах, как случайный взвешенный граф [3], в котором вершины представляют собой врачей, а ребра - их контакты друг с другом.

Вершины графа распределялись по пространству в соответствии со случайным равномерным распределением, причем, если расстояние между ними оказывалось меньше r отн. ед., то они объединялись в один.

Для каждой вершины определялась степень - количество ребер, выходящих или входящих в ее (степень контактности врача). В графе так же выделялась особая вершина - первичный источник информации, с которой начиналось распространение информации о новом лекарственном средстве.

Вершины графа соединялись ребрами случайным образом. Для ребер назначались веса - степени торможения скорости передачи информации от врача к врачу, в соответствии со случайным равномерным распределением из $(0 ; 1)$. Так же веса могут назначаться в соответствии со степенями двух соединяемых ребром вершин, например, как среднее.

Для полученного случайного взвешенного графа определялось кратчайшее расстояние от вершины источника до интересующей, например, самой удаленной. Для расчета расстояния между вершинами применялся алгоритм Дейкстры с учетом весов [4].

Предложенная модель была реализована в среде MATLAB по причине наличия в ней специализированных инструментов, обеспечивающих удобную работу с графами (Graph Toolbox) и обработку результатов расчетов [5].

Входными данными для моделирования служили количество вершин, на основе которых генерировался случайный взвешенный граф, а так же номера вершин источника и интересующего приемника информации, для которых рассчитывалось кратчайшее расстояние.

На рисунке 1 приведено изображение графа распространения инновационного лекарственного средства среди 10 врачей. Положим, например, что источником распространения нового лекарственного средства является врач 1 , приемником - 9. Тогда в кратчайший путь включены вершины $1,3,2,9$ и соединяющие их ребра. Длина такого пути равна $\mathrm{d}=1.2395$ отн.ед. 


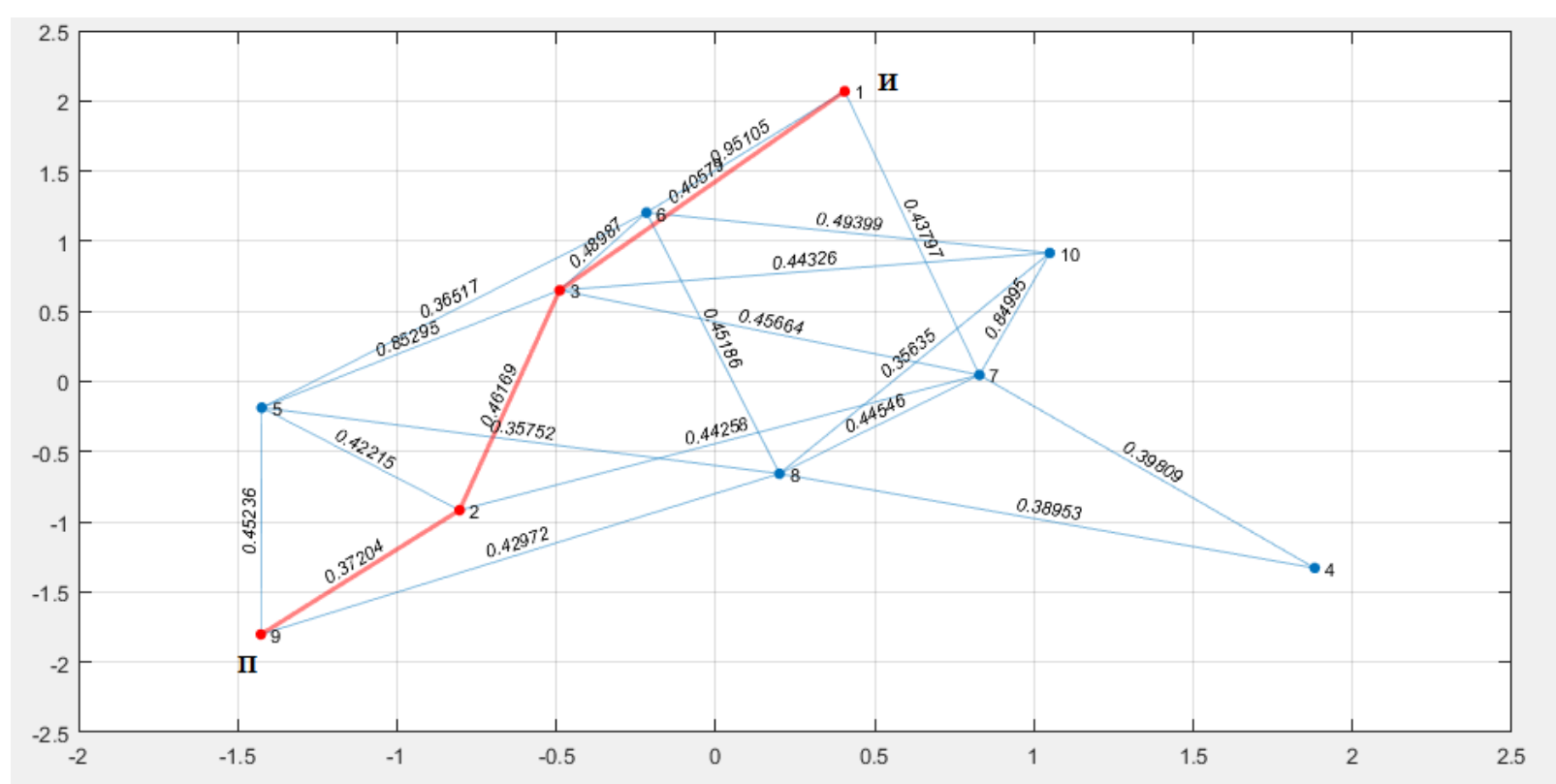

Рис. 1 - Граф распространения инновационного лекарственного средства в сети из 10 врачей

Расчет степени вершин для сгенерированного графа позволяет проанализировать структуру сети распространения инновационного лекарственного средства. Так в качестве вершины, где располагается источник, очевидно, лучше всего выбирать с наибольшей степенью, т.е. врача с максимальным количеством контактов. С другой стороны, вершины с минимальной степенью (врачи с минимальным количеством контактов) не являются наилучшим выбором для источника информации.

На рисунке 2 приведено изображение графа распространения инновационного лекарственного средства среди 15 врачей, а так же указан кратчайший путь от вершины с максимальной степенью до произвольной (отмечен красным) и до вершины с минимальной (отмечен зеленым). Источник (И) - узел 5 с максимальной степенью 11. Кратчайший путь от вершины 5 до произвольной, например, 10 (П1 - красная линия) содержит в себе вершины 5, 9, 10, его вес равен 0.8087. Кратчайший путь от вершины 5 до вершины 15 (П2 - зеленая линия) с минимальной степенью, равной 3 , проходит через вершины $5,1,15$, его вес составляет 0. 0.7758. Таким образом, сгенерирована достаточно удобная сеть распространения информации об инновационного лекарственного средства, когда источником распространения служит врач с максимальным количеством контактов, расположенный в центре, что обеспечивает минимальные величин торможения, когда вес пути до наименее контактного врача может оказаться даже меньше чем до произвольного.

Кроме этого, оценивая среднюю степень вершин графа, можно оценить количество контактов врача, необходимое для быстрого распространения информации по сети. Например, для графа из рис 2 она составляет 7, таким образом, вершины 7, 10, 14, 5 со значениями 4, 4, 6, 3 соответственно, могут рассматриваться как малоконтактные врачи и могут быть активнее вовлечены в 
процесс распространения информации об инновационном лекарственном средстве.

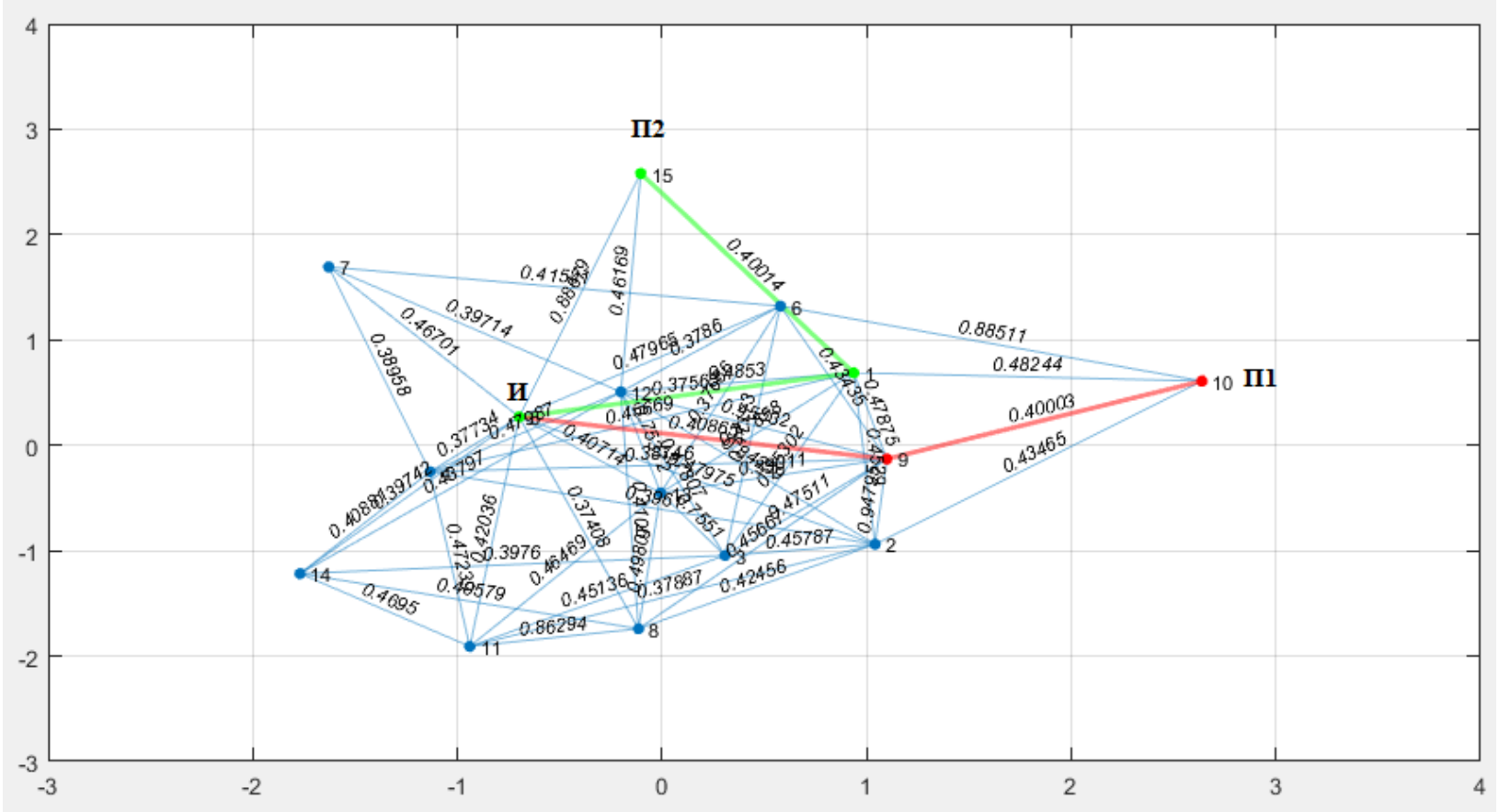

Рис. 2 - Граф распространения инновационного лекарственного средства в сети из 15 врачей и кратчайшие пути

Таким образом, предложенная модель, при переходе к абсолютным единицам, позволяет оценить и спрогнозировать процесс распространения информации о новом лекарственном средстве в профессиональной социальной сети врачей и может быть применима при управлении данным процессом с целью достижения наибольшей скорости и экономического эффекта.

\section{Список литературы}

1. Тищенко, В. И. Инновационные проекты в сфере медицинской промышленности/В. И. Тищенко, Т. И. Жукова// Труды ИСАРАН. - 2008. - Т. 34. - С. 305-323.

2. Бердникова, Е. Ф. Инновационное развитие здравоохранения/Е. Ф.Бердникова//Вестник Казанского технологического университета. - 2013. T. 14. - № 15. - С. 300-305.

3. Домнин, Л.Н. Элементы теории графов: учебное пособие/ Л.Н. Домнин. - Пенза: Изд-во ПГУ, 2007. - 144 с.

4. Зябиров, Э.В. Методы определения кратчайшего пути между вершинами графа / Э.В. Зябиров, С.П. Токарев, Л.И. Федосеева // Успехи современного естествознания. - 2011. - № 7. - С. 113-114.

5. Иглин, С. П. Математические расчеты на базе MATLAB. / С. П. Иглин. - СПб. : БХВ-Петербург, 2005. - 634 с. 